\title{
Analysis of 116 cases of rectal cancer treated by transanal local excision
}

\author{
Gongping Sun, Yuanxin Tang, Xiaoxia Li*, Jin Meng and Gaofeng Liang
}

\begin{abstract}
Background: The purpose of this research was to evaluate the therapeutic effects and prognostic factors of transanal local excision (TAE) for rectal cancer.

Methods: We retrospectively analyzed 116 cases that underwent TAE for rectal cancer from 1995 to 2008. A Cox regression analysis was used to analyze prognostic factors.

Results: The survival times for the patients were from 14 to 160.5 months (median time, 58.5 months). The 5-year and 10 -year overall survival rates were $72 \%$ and $53 \%$, respectively. In all 16 cases experienced local recurrence (13.8\%). Pathological type, recurrence or metastasis, and depth of infiltration ( $T$ stage) were the prognostic factors according to the univariate analysis, and the latter two were independent factors affecting patient prognosis. For patients with $\mathrm{T} 1$ stage who underwent adjuvant radiotherapy, there was no local recurrence; for those in T2 stage, the local recurrence rate was $14.6 \%$. In addition, there was no difference between the patients who received radiotherapy and those who did not (T1: $P=0.260, T 2: P=0.262$ for survival rate and T1: $P=0.480, T 2: P=0.560$ for recurrence).
\end{abstract}

Conclusions: The result of TAE for rectal cancer is satisfactory for T1 stage tumors, but it is not suitable for T2 stage tumors.

Keywords: rectal cancer, transanal local excision, survival, recurrence, radiotherapy

\section{Highlights}

- Material for rectal cancer patients who underwent TAE were retrospectively collected.

- Survival rate and recurrence rate of the patients were analyzed.

- Recurrence or metastasis and depth of infiltration were prognostic factors.

- Adjuvant radiotherapy caused no significant clinical outcomes.

- Patients in T2 stage had a higher local recurrence rate.

\section{Background}

Rectal cancer is the result of uncontrolled cell growth in the colon or rectum (parts of the large intestine), or in the appendix. It is a significant source of morbidity and mortality. The mortality rate in mainland China began to increase from 1995, especially in urban areas [1,2]. Low rectal cancer

*Correspondence: XiaoxiaLixx13@163.com

Department of Gastrointestinal Surgery, The Fourth Affiliated Hospital of the China Medical University, No. 4 Chongshan Road, Shenyang 110032, China accounts for approximately $70 \%$ of the rectal cancers in China [3]. Surgical excision of the affected segment of the bowel is the mainstay treatment for rectal cancer [4].

Transanal local excision (TAE) is an acceptable curative operation for low rectal cancer [5]. This treatment at an early stage has multiple advantages, including noninvasion of the abdominal cavity, minimal trauma and no disturbance of urinary and sexual functions [6]. Meanwhile, TAE also makes it possible to avoid postoperative colostomy $[7,8]$. Currently, there are controversies about patient selection for TAE treatment. In this retrospective study, we investigated the efficacy of TAE treatment for rectal cancer patients at an early stage, as well as the prognostic factors in this treatment.

\section{Methods}

\section{Patients}

Clinical material for patients with rectal cancer treated between 1995 and 2008 by TAE at Liaoning Cancer Hospital and the Fourth Affiliated Hospital of the China Medical University were collected. The patients underwent a 
computed tomography (CT) scan, magnetic resonance imaging (MRI) scan and digital rectal examination. Patients within stage II of rectal cancer according to the National Comprehensive Cancer Network (NCCN) guideline were included, while those at a higher stage or who did not agree to the TAE regimen were excluded.

\section{Treatments}

\section{Surgical treatment}

Preoperatively, evaluation of the tumors, including location, size, and stage, was performed using an enteroscope, pelvic CT/MRI and digital rectal examination [9]. Then, all tumors were treated by TAE. Dorsal lithotomy or the prone jackknife position was used according to the location of the tumor, that is, the distance from the anal verge to the distal tumor margin. Firstly, routine sterilization was conducted, followed by a 4- or 5-fingerwide expansion of the anus. Secondly, after groovy disinfection, the tumors were exposed. Finally, the tumors, together with the basal part and normal tissues within $1 \mathrm{~cm}$ of the lesions, were excised entirely. The excised specimens, resection margins and the basal parts were sent for pathological examination.

\section{Adjuvant radiation therapy}

After TAE surgery, 52 patients received adjuvant radiation therapy (RT) with the energy ranging from 6 to $10 \mathrm{MV}$ according to their tolerance degree and the dose limitation for intestinal radiation. The detailed treatments including the radiation doses are presented in Table 1.

\section{Statistical analysis}

Survival analysis was performed with the SPSS 15.0 package. The Cox proportional hazard model was used to analyze the prognostic factors. The univariate analysis used the Kaplan-Meier method, survival rates were assessed using a life table and comparisons between survival rates were performed using a log rank test $(\alpha=0.05)$.

\section{Results}

\section{Clinical material}

A total of 116 cases (53 male and 63 female; 0.8:1.0) were included in this retrospective study. Their ages ranged from 30 to 80 with a median of 61 . Preoperatively, 34 cases were diagnosed as T1, 77 cases as T2, and 5 cases as

Table 1 Radiotherapy treatment for 52 patients

\begin{tabular}{lll}
\hline Radioactive source & Doses (Gy) & Number of cases \\
\hline Cs-137 & $15-50$ & 13 \\
Ir-192 & 45 & 2 \\
Cs-137 and Ir-192 & $15+30$ & 2 \\
Co-60 & $10-60$ & 14 \\
X-ray & $21-67$ & 21 \\
\hline
\end{tabular}

T3 cancers; and postoperatively, 7 cases were diagnosed as Tis, 24 cases as T1, 81 cases as T2, and 4 cases as T3. Besides, 52 patients received RT. All patients were treated with TAE, while one patient undertook a second TAE treatment. Six patients converted to a Miles operation, and one patient converted to a low anterior resection. Complications after the operation occurred in six cases (5.2\%), among which five cases had a hemorrhage of more than $50 \mathrm{ml}$ during the operation, and the bleeding was controlled after sufficient hemostatic measures and symptomatic treatment. One case developed a portal vein infection and septicemia, and the condition improved after anti-infective treatment.

\section{Follow-up and survival analysis}

Two patients were lost to follow-up, while the follow-up rate was $98.3 \%$. The survival time was 14 to 160.5 months, of which the median was 58.5 months. The 5 -year and 10year overall survival rates were $72 \%$ and $53 \%$, respectively. In total, 16 patients developed a local recurrence of the tumor during the follow-up period (recurrence rate, $13.8 \%$ ), while distant metastasis occurred in 13 cases (11.2\%), and local recurrence combined with metastasis occurred in 3 cases (2.6\%).

\section{Efficacy of adjuvant radiation therapy}

Statistical comparisons of the survival rate and recurrence rate were performed between patients who received TAE and those received both TAE and adjuvant RT at the T1 and T2 stages (Table 2). No statistical difference in survival rate was found between the two groups (T1: $P=0.184$ (Figure 1A); T2: $P=0.356$ (Figure 1B)). In addition, there were also no significant differences in local recurrence rate between the TAE and TAE + RT groups at the T1 $(P=0.480$, Figure $1 C)$ and T2 stages $(P=0.560$, Figure $1 \mathrm{D})$.

\section{Analysis of prognostic factors}

We investigated the prognostic factors for TAE treatment using univariate analysis (Table 3). We found that pathological type, recurrence or metastasis, and depth of infiltration (T stage) were the prognostic factors. In the further Cox regression analysis, we detected that among the prognostic factors, recurrence or metastasis, and depth of infiltration were independent factors (Table 4) affecting patients' prognosis. Patients with a higher $\mathrm{T}$ stage or with recurrence or metastasis have a higher risk of death.

\section{Discussion}

Reducing surgical complications and preserving the function of the anal sphincters are increasingly the focus of treatment of early local rectal cancer at stages $\mathrm{T} 1$ and T2. Local excision of rectal cancers, including TAE, transanal endoscopic resection and transsacral local 
Table 2 Survival and postoperative local recurrence for the T1 and T2 patients

\begin{tabular}{|c|c|c|c|c|c|c|c|}
\hline \multirow[t]{2}{*}{ Stage } & \multirow[t]{2}{*}{ Therapy } & \multirow{2}{*}{$\begin{array}{l}\text { Number } \\
\text { of cases }\end{array}$} & \multirow{2}{*}{$\begin{array}{l}\text { Median survival } \\
\text { time (months) }\end{array}$} & \multicolumn{2}{|c|}{ Survival rate (\%) } & \multicolumn{2}{|c|}{ Local recurrence (\%) } \\
\hline & & & & 5-year & 10-year & 5-year & 10-yea \\
\hline \multirow[t]{2}{*}{$\mathrm{T1}$} & TAE & 16 & 67 & 75 & 38 & 6.3 & 6.3 \\
\hline & $\mathrm{TAE}+\mathrm{RT}$ & 8 & 99 & 63 & 50 & 0 & 0 \\
\hline \multirow[t]{2}{*}{$\mathrm{T} 2$} & TAE & 40 & 44 & 30 & 10 & 10.0 & 15.0 \\
\hline & $\mathrm{TAE}+\mathrm{RT}$ & 41 & 69 & 61 & 34 & 7.3 & 14.6 \\
\hline
\end{tabular}

$\mathrm{RT}$, radiation therapy; TAE, transanal local excision.

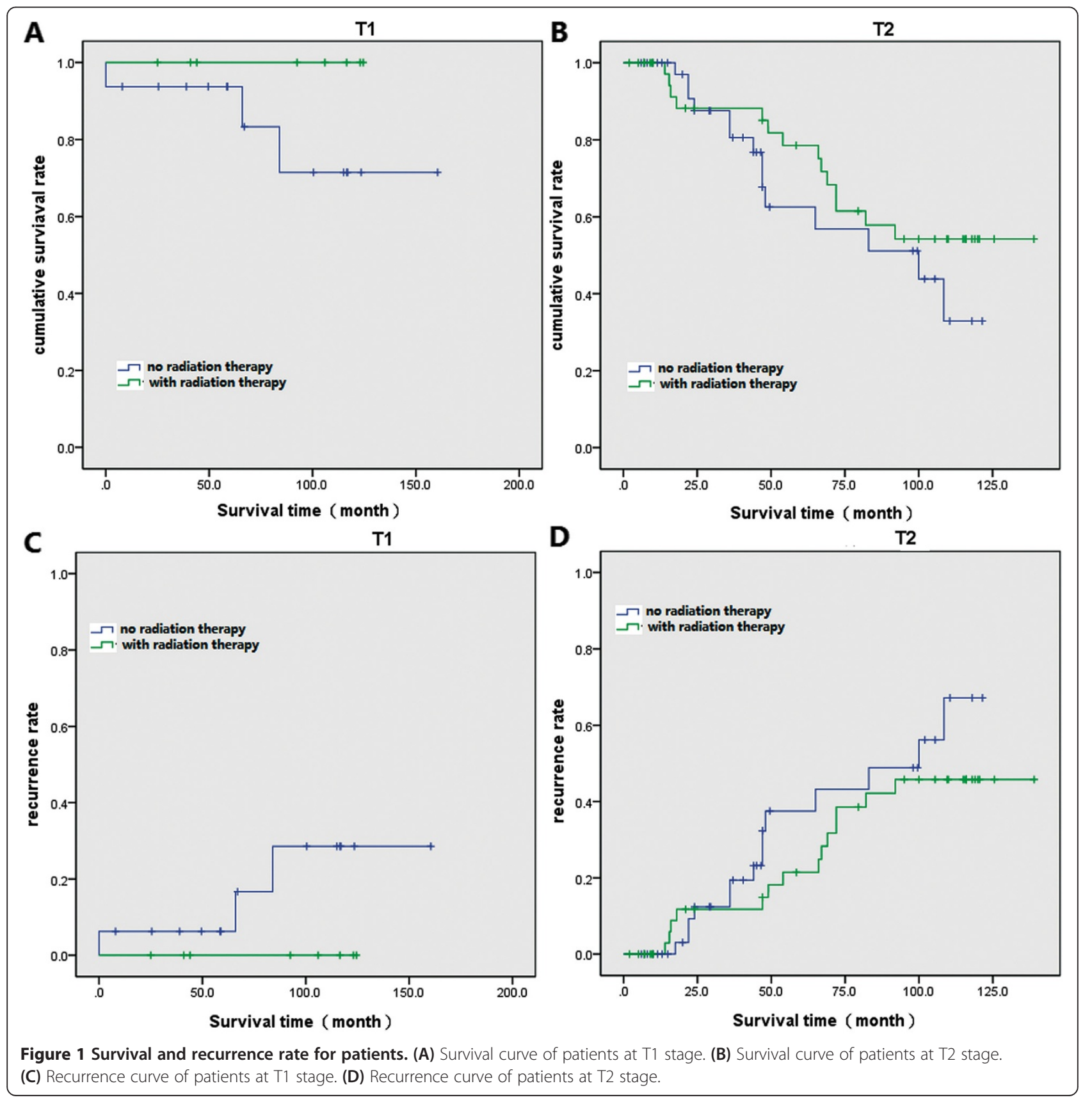


Table 3 Univariate analysis of the prognostic factors

\begin{tabular}{|c|c|c|c|c|}
\hline \multirow[b]{2}{*}{ Clinical features } & \multirow[b]{2}{*}{ Cases (\%) } & \multicolumn{2}{|c|}{ Survival rate (\%) } & \multirow[b]{2}{*}{$P$} \\
\hline & & 5-year & 10-year & \\
\hline \multicolumn{5}{|l|}{ Sex } \\
\hline Male & $53(45.7)$ & 64 & 58 & 0.912 \\
\hline Female & $63(54.3)$ & 77 & 49 & \\
\hline Radiotherapy & & 116 & & 0.623 \\
\hline Yes & $52(44.8)$ & 75 & 55 & \\
\hline No & $64(55.2)$ & 69 & 51 & \\
\hline Recurrence or metastasis & 116 & & & $<0.01$ \\
\hline Yes & $32(27.6)$ & 32 & - & \\
\hline No & $84(72.4)$ & 83 & 72 & \\
\hline Tumor diameter, $d(\mathrm{~cm})$ & 116 & & & 0.928 \\
\hline$d<4 \mathrm{~cm}$ & $109(94.0)$ & 71 & 54 & \\
\hline$d \geq 4 \mathrm{~cm}$ & $7(6.0)$ & 75 & - & \\
\hline Distance to anal margin, $L(\mathrm{~cm})$ & 115 & & & 0.128 \\
\hline$L<4 \mathrm{~cm}$ & $37(32.2)$ & 87 & 58 & \\
\hline$L \geq 4 \mathrm{~cm}$ & $78(67.8)$ & 67 & 51 & \\
\hline Proportion of tumor basal part, $C$ & 94 & & & 0.269 \\
\hline $1 / 3<C$ & $69(73.4)$ & 69 & 52 & \\
\hline $1 / 3 \leq C<2 / 3$ & $24(25.5)$ & 70 & 46 & \\
\hline$C \geq 2 / 3$ & $1(1.1)$ & 100 & - & \\
\hline Gross type & 101 & & & 0.168 \\
\hline Protrusive & $72(71.3)$ & 76 & 58 & \\
\hline Ulcerative & $27(26.7)$ & 42 & 34 & \\
\hline Infiltrative & $2(2.0)$ & 100 & - & \\
\hline Pathological type & 115 & & & 0.025 \\
\hline Well differentiated & $80(69.6)$ & 79 & 57 & \\
\hline Moderately differentiated & 19 (16.5) & 50 & 30 & \\
\hline Poorly differentiated & $16(13.9)$ & 66 & 57 & \\
\hline Depth of infiltration & 116 & & & 0.002 \\
\hline Tis & $7(6.0)$ & 100 & 83 & \\
\hline $\mathrm{T} 1$ & $24(20.7)$ & 93 & 85 & \\
\hline $\mathrm{T} 2$ & $81(69.8)$ & 60 & 45 & \\
\hline T3 & $4(3.4)$ & 50 & - & \\
\hline
\end{tabular}

resection, has been practiced for tens of years. Studies have constantly shown that for rectal cancer patients with tumors confined to the rectal wall, the outcomes of local excision are usually satisfactory $[10,11]$. Thus, local excision in the treatment of early rectal cancers is helpful and should be studied intensively.

Local excision of rectal cancers is an optional therapy for patients without lymph node metastasis, and its application depends on the depth of tumor infiltration, tumor differentiation and the extent of invasion to lymphatic and blood vessels $[9,12]$. According to treatment guidelines recommended by NCCN together with our clinical experience and most researchers' viewpoints [13,14], we propose the indications for local excision should include: (1) a well-differentiated adenocarcinoma; (2) the depth of tumor invasion is at the Tis to T1 stage; (3) distal rectal cancer within $8 \mathrm{~cm}$ of the anal margin; (4) the diameter of the tumor is less than $3.0 \mathrm{~cm}$ and involves no more than $1 / 3$ of the rectal perimeter; (5) no vascular infiltration; (6) no lymph node and distal metastasis; and (7) patient cannot tolerate major surgery or has developed severe complications.

Since lymph node dissection is impossible in a local excision, accurate preoperative staging is especially 


\begin{tabular}{llll}
$\begin{array}{l}\text { Table } 4 \text { Multivariate Cox regression analysis of } \\
\text { prognostic factors }\end{array}$ & \multicolumn{1}{l}{} \\
\hline Clinical features & $\boldsymbol{P}$ & Exp (B) & $\mathbf{9 5 . 0 \%}$ confidence interval \\
\hline Sex & 0.131 & 2.076 & $0.805-5.355$ \\
Age & 0.186 & 1.022 & $0.990-1.056$ \\
Tumor diameter & 0.434 & 1.270 & $0.698-2.312$ \\
Distance to anal margin & 0.410 & 0.862 & $0.607-1.226$ \\
Width of tumor basal part & 0.216 & 0.033 & $0.000-7.369$ \\
Gross type & 0.610 & 1.251 & $0.529-2.956$ \\
Pathological type & 0.305 & 1.304 & $0.785-2.165$ \\
T stage & 0.042 & 2.622 & $1.037-6.625$ \\
Adjuvant radiotherapy & 0.163 & 0.480 & $0.172-1.345$ \\
Recurrence or metastasis & $<0.001$ & 3.025 & $1.985-4.611$
\end{tabular}

important in determining whether to use this method or not. The widely used staging measures include digital rectal examination, enteroscopy, endorectal ultrasonography, spiral CT, rectal MRI and positron emission tomography-CT [15-17]. We adopted CT, MRI and digital rectal examination.

The 5-year survival rates after a Miles resection, low anterior resection and ultra-low anterior resection are $70.3 \%, 72.9 \%$ and $73.7 \%$, respectively, and for patients at stage I, the rate is $90.9 \%[7,9]$. In our study, the overall 5 -year survival rate was $72 \%$, while the rates for $\mathrm{T} 1$ and T2 patients were $93 \%$ and $63 \%$. This result demonstrates that for strictly selected cases, local excision is more suitable for $\mathrm{T} 1$ patients. In addition, the recurrence rate of T2 tumors in this study was far higher than that of T1 tumors, consistent with previous studies $[18,19]$. Therefore, we do not recommend the application of local excision for rectal cancer patients at stage T2.

Most relevant studies have reported that the reason for the high recurrence after local excision mainly lies in two aspects. One is the seeding implantation of cancer cells during the surgery. Though many clinicians recommend a washout during the operation, this does not necessarily lead to a reduction in the incidence of local recurrence [10]. In comparison, under the principles of no contact and whole resection, standard manipulations and appropriate case selection are more effective in preventing implantation of malignant cells. TAE is difficult to perform, and the field exposure is also very limited. The extent of the technical difficulty of a whole tumor excision is determined by multiple factors, including the tumor's gross type, involved perimeter of rectal wall, distance from the anal margin, and patient's age and obesity. In the NCCN guideline, one of the standards for TAE is a tumor diameter less than $3 \mathrm{~cm}$, but there are also arguments that a standard of $2.5 \mathrm{~cm}$ might be more statistically significant [20]. For rectal cancers with low hazard factors, if the field is clear and manipulation is simple, then the tumor can be entirely excised while avoiding implantation of malignant cells.

The other chief factor responsible for the high recurrence after local excision is potential lymph node metastasis and insufficient excision of the marginal area. The probability of lymph node metastasis increases as T stage advances: at the T1 stage it is 0 to $12 \%$, at the T2 stage it is 12 to $18 \%$, and at the T3 and T4 stages it is up to 36 to $79 \%$ [10]. For rectal cancers involving the mucosa or submucosa, the probability of lymph node metastasis is $3 \%$ to $5 \%$, thus local excision is a theoretically cure treatment. But for those with an infiltrated muscular layer, because the probability of lymph node metastasis is as high as $40 \%$, it would be more prudent to consider adopting TAE to treat T2 rectal cancers. Our statistical analysis showed that as the $\mathrm{T}$ stage increases the incidence of postoperative recurrence tends to be higher, being $6.3 \%$ for $\mathrm{T} 1$ and $14.8 \%$ for $\mathrm{T} 2$, which is in accordance with other reports $[8,21,22]$. Therefore, local excision is only a palliative therapy.

This study shows that adjuvant radiotherapy can significantly decrease the recurrence hazards of T1 and T2 rectal cancer patients, but was not related to their clinical outcomes (T1: $P=0.184$; T2: $P=0.356$ ). The multimodality treatment schemas combining local excision and radiotherapy have been reported to be able to improve the local control rates, as well as better functional outcomes in patients with higher stage of rectal cancer $[23,24]$. Though no conclusion has been reached regarding the standards of the pre- and postoperative radiotherapy, and related background factors (such as the doses), most reports have indicated that compared with sole surgical treatment, surgery combined with preoperative radiotherapy can enhance the survival rate and lower the incidence of recurrence. Also, local excision was considered as an extended indication for T2-3 rectal cancer patients after neoadjuvant chemoradiotherapy [25]. Local excision is efficient in treating T2 patients with distal rectum cancer who exhibit complete pathologic response to preoperative chemoradiation [26]. However, in comparison, surgery with a postoperative radiotherapy will only decrease the tendency of recurrence while impose on effect on the survival rate $[27,28]$. Therefore, preoperative radiotherapy is strongly recommended for rectal patients.

\section{Conclusion}

Our statistical analysis of the 116 TAE-treated rectal cancer cases indicates that TAE is an effective therapy for T1 cancers but it is not suitable for patients at the T2 stage. Tumor pathological type, recurrence or metastasis, and invasion depth ( $\mathrm{T}$ staging) are all factors affecting patient prognosis. Tumors that are poorly differentiated and deeply infiltrated, and those with recurrence or metastasis, tend to have poor outcomes. Recurrence or metastasis 
and tumor infiltration depth are independent factors influencing survival conditions, and they could increase the hazard of death. Adjuvant radiotherapy could decrease the danger of local recurrence after surgery, but may not improve the survival rate. It can be considered a complementary and auxiliary therapeutic measure.

\section{Abbreviations}

CT: computed tomography; MRI: magnetic resonance imaging; NCCN: National Comprehensive Cancer Network; TAE: transanal local excision.

\section{Competing interests}

The authors declared that they have no competing interests.

\section{Authors' contributions}

GS and YT participated in the design of this study, and they both performed the statistical analysis. $\mathrm{XL}$ carried out the study, and, together with $\mathrm{JM}$, collected important background information, and drafted the manuscript. GL conceived of this study, participated in the design and helped to draft the manuscript. All authors read and approved the final manuscript.

\section{Acknowledgements}

This study was supported by the natural science fund project in Liaoning province (No 201102281).

\section{Received: 25 March 2014 Accepted: 12 June 2014}

Published: 9 July 2014

\section{References}

1. Yu D-S, Huang X-E, Zhou J-N: Comparative study on the value of anal preserving surgery for aged people with low rectal carcinoma in Jiangsu, China. Asian Pac J Cancer Prev 2012, 13:2339-2340.

2. Paun BC, Cassie S, MacLean AR, Dixon E, Buie WD: Postoperative complications following surgery for rectal cancer. Ann Surg 2010, 251:807-818.

3. Bao-ming Y: Progress in the diagnosis and treatment of lower rectal cancer. Chin J Practical Hand Surg 2002, 22:34-37.

4. Chang GJ, Rodriguez-Bigas MA, Skibber JM, Moyer VA: Lymph node evaluation and survival after curative resection of colon cancer: systematic review. J Natl Cancer Inst 2007, 99:433-441.

5. Zhou X, Huang X-E, Zhang T, Shang J-Q, Guan X, Zhong J, Feng B, Sun Y, Zhou J-N: Extended full-thickness transanal local excision to treat ultra-low rectal cancer: an initial clinical exploration. Asian Pac J Cancer Prev 2011, 12:1045-1048.

6. Gao J-D, Shao Y-F, Bi J-J, Shi S-S, Liang J, Hu Y-H: Local excision carcinoma in early stage. World J Gastroenterol 2003, 9:871-873.

7. Nastro P, Beral D, Hartley J, Monson JR: Local excision of rectal cancer: review of literature. Dig Surg 2005, 22:6-15.

8. Sengupta S, Tjandra JJ: Local excision of rectal cancer. Dis Colon Rectum 2001, 44:1345-1361.

9. Garcia-Aguilar J, Mellgren A, Sirivongs P, Buie D, Madoff RD, Rothenberger DA: Local excision of rectal cancer without adjuvant therapy: a word of caution. Ann Surg 2000, 231:345.

10. Mellgren A, Sirivongs $P$, Rothenberger DA, Madoff RD, García-Aguilar J: Is local excision adequate therapy for early rectal cancer? Dis Colon Rectum 2000, 43:1064-1071.

11. Sharma A, Hartley J, Monson JR: Local excision of rectal tumours. Surg Oncol 2003, 12:51-61.

12. Compton CC: Colorectal carcinoma: diagnostic, prognostic, and molecular features. Mod Pathol 2003, 16:376-388.

13. Benson A 3rd, Choti M, Cohen A, Doroshow J, Fuchs C, Kiel K, Martin E Jr, McGinn C, Petrelli N, Posey J: NCCN practice guidelines for colorectal cancer. Oncology (Williston Park, NY) 2000, 14:203.

14. Graham RA, Hackford AW, Wazer DE: Local excision of rectal carcinoma: a safe alternative for more advanced tumors? J Surg Oncol 1999, 70:235-238.

15. Brown G, Davies S, Williams G, Bourne M, Newcombe R, Radcliffe A, Blethyn J, Dallimore N, Rees B, Phillips C: Effectiveness of preoperative staging in rectal cancer: digital rectal examination, endoluminal ultrasound or magnetic resonance imaging? $\mathrm{Br} J$ Cancer 2004, 91:23-29.
16. Hundt W, Braunschweig R, Reiser M: Evaluation of spiral $C T$ in staging of colon and rectum carcinoma. Eur Radiol 1999, 9:78-84.

17. Veit-Haibach P, Kuehle CA, Beyer T, Stergar H, Kuehl H, Schmidt J, Börsch $G$ Dahmen G, Barkhausen J, Bockisch A: Diagnostic accuracy of colorectal cancer staging with whole-body PET/CT colonography. JAMA 2006, 296:2590-2600.

18. Weiser MR, Landmann RG, Wong WD, Shia J, Guillem JG, Temple LK, Minsky BD, Cohen AM, Paty PB: Surgical salvage of recurrent rectal cancer after transanal excision. Dis Colon Rectum 2005, 48:1169-1175.

19. Lee W, Lee D, Choi S, Chun H: Transanal endoscopic microsurgery and radical surgery for T1 and T2 rectal cancer. Surg Endosc 2003, 17:1283-1287.

20. Xin-shu D, Peng Z, Zhi-wei Y, Xi-shan W: Patterns and treatment of local recurrence after rectal carcinoma operation. Chin J Practical Hand Surg 2002, 22:334-336.

21. Greenberg JA, Shibata D, Herndon JE II, Steele GD Jr, Mayer R, Bleday R: Local excision of distal rectal cancer: an update of cancer and leukemia group B 8984. Dis Colon Rectum 2008, 51:1185-1194.

22. Chang AJBA, Nahas CSR, Araujo SEA, Nahas SC, Marques CFS, Kiss DR, Cecconello I: Early rectal cancer: local excision or radical surgery? I Surg Educ 2008, 65:67-72

23. Sauer R, Becker H, Hohenberger W, Rödel C, Wittekind C, Fietkau R, Martus $P$, Tschmelitsch J, Hager E, Hess CF: Preoperative versus postoperative chemoradiotherapy for rectal cancer. N Engl I Med 2004, 351:1731-1740.

24. Valentini V, Aristei C, Glimelius B, Minsky BD, Beets-Tan R, Borras JM, Haustermans K, Maingon P, Overgaard J, Pahlman L: Multidisciplinary rectal cancer management: 2nd European rectal cancer consensus conference (EURECA-CC2). Radiother Oncol 2009, 92:148-163.

25. Borschitz T, Wachtlin D, Möhler M, Schmidberger $H$, Junginger T: Neoadjuvant chemoradiation and local excision for T2-3 rectal cancer. Ann Surg Oncol 2008, 15:712-720.

26. Kim CJ, Yeatman TJ, Coppola D, Trotti A, Williams B, Barthel JS, Dinwoodie W, Karl RC, Marcet J: Local excision of T2 and T3 rectal cancers after downstaging chemoradiation. Ann Surg 2001, 234:352.

27. Taylor RH, Hay JH, Larsson SN: Transanal local excision of selected low rectal cancers. Am J Surg 1998, 175:360-363.

28. Visser BC, Varma MG, Welton ML: Local therapy for rectal cancer. Surg Oncol 2001, 10:61-69.

doi:10.1186/1477-7819-12-202

Cite this article as: Sun et al:: Analysis of 116 cases of rectal cancer treated by transanal local excision. World Journal of Surgical Oncology 2014 12:202.

\section{Submit your next manuscript to BioMed Central and take full advantage of:}

- Convenient online submission

- Thorough peer review

- No space constraints or color figure charges

- Immediate publication on acceptance

- Inclusion in PubMed, CAS, Scopus and Google Scholar

- Research which is freely available for redistribution 